\title{
OPTIMASI PROSES EPOKSIDASI ASAM OLEAT PADA SCALING UP SINTESIS ASAM 9,10-DIHIDROKSI STEARAT (DHSA) BENCH SCALE
}

\section{OPTIMIZATION ON EPOXIDATION OF OLEIC ACID AT SCALING UP SYNTHESIS OF 9.10-DIHYDROXYSTEARATE ACID (DHSA) BENCH SCALE}

\author{
Maisaroh, dan Wiwik Handayani \\ Pusat Teknologi Agroindustri, Badan Pengkajian dan Penerapan Teknologi, \\ LAPTIAB Gedung 611-612, Kawasan Puspiptek-Serpong, \\ Telp.: (021)7560758 Ex. 7423 \\ e-mail : maisaroh@bppt.go.id
}

\begin{abstract}
Abstrak
Sintesis asam 9,10-dihidroksi stearat (DHSA) dari asam oleat terepoksidasi merupakan salah satu upaya yang akan meningkatkan penggunaan, diversifikasi dan nilai tambah minyak kelapa sawit. Scaling up proses epoksidasi asam oleat dari skala laboratorium ke bench scale (kapasitas 5 L)terjadi perubahan volume dan geometri dari peralatan yang akan mempengaruhi proses epoksidasi itu sendiri sehingga perlu dilakukan observasi terhadap parameter-parameter yang akan digunakan dalam basic dan engineering design.Tujuan dari penelitian ini adalah melakukan scaling up proses dari skala laboratorium ke bench scale (kap. $5 \mathrm{~L}$ ) epoksidasi asam oleat sebagai produk antara sintesis DHSA dalam pengembangan produk turunan kelapa sawit yang akan digunakan sebagai bahan kosmetik.Scaling Up epoksidasi asam oleat dengan asam performat yang dibentuk secara in situ dilakukan menggunakan reaktor 5 liter dengan perbandingan mol asam oleat : asam format : hidrogen peroksida $50 \%=1: 1,25: 6$. Produk epoksidasi ini akan dilanjutkan untuk dihidroksilasi pada sintesis DHSA sebagai bahan kosmetik.
\end{abstract}

Kata kunci: epoksidasi, scaling up, DHSA, bench scale, bahan kosmetik.

\begin{abstract}
The synthesis of 9,10-dihydroxystearate acid (DHSA) of epoxidized oleic acid is one of the efforts that will increase the use, diversification and value added of palm oil. Scaling up the process of epoxidizing oleic acid from the laboratory scale to the bench scale ( 5 capacity) changes the volume and geometry of the apparatus that will affect the epoxidation process itself so that it is necessary to observe the parameters to be used in basic and engineering design. The purpose of this study is to scaling up the proses from laboratory scale to bench scale (epoxidation of oleic acid) as a intermediete product of DHSA synthesis in the development of palm oil derivative products to be used as cosmetic ingredients. Scaling Up epoxidation of oleic acid with the in situ formed acid is carried out using a 5-liter reactor with a mole ratio of oleic acid: formic acid: $50 \%$ hydrogen peroxide $=1: 1.25: 6$. This epoxidation product will be continued for hydroxylation at DHSA synthesis as a cosmetic ingredient.
\end{abstract}

Keywords: epoxidation, scaling up, DHSA, bench scale, cosmetic ingredients.

Diterima (received) : 03 Januari 2018, Direvisi (revised ) : 06 Februari 2018

Disetujui (accepted) : 22 Maret 2018 


\section{PENDAHULUAN}

Asam 9,10-dihidroksi stearat (DHSA) dengan rumus molekul $\mathrm{C}_{18} \mathrm{H}_{36} \mathrm{O}_{4}$ merupakan senyawa hidroksil asam lemak yang memiliki sifat yang unik untuk berbagai aplikasi antara lain sebagai emulsifier antara fasa minyak/lilin gel dan air dalam formulasi kosmetik. DHSA memiliki berat molekul $316,476 \mathrm{~g} / \mathrm{mol}$, merupakan asam lemak rantai panjang yang mengandung dua gugus hidroksil didalam struktur molekulnya ${ }^{1)}$. Struktur unik DHSA yang memiliki gugus fungsi hidroksi $(-\mathrm{OH})$ dan gugus fungsi karboksil $(-\mathrm{COOH})$, diterjemahkan ke dalam sifat-sifat yang menarik seperti polaritas yang baik, berperilaku seperti asam lemak rantai panjang dan dapat dengan mudah mengikat senyawa polar ${ }^{2}$. Secara alami DHSA dapat diperoleh dari minyak jarak dalam jumlah sedikit yaitu $1 \% 3{ }^{3)}$.

Saat ini, DHSA telah sukses dihasilkan dari asam oleat berbasis kelapa sawit, melalui epoksidasi dengan asam performat (rute PFA) atau asam perasetat (rute PAA) diikuti oleh hidrolisis epoksida menggunakan katalis asam sulfat ${ }^{4)}$. Peningkatan proses untuk produksi hidroksil asam lemak berbasis kelapa sawit (DHSA) telah dipatenkan oleh Ahmad et al.20095). Menurut Ahmad et al.2009, asam oleat teroksidasi oleh asam performat yang dibentuk secara in situ, dengan adanya hidrogen peroksida dan sejumlah katalis asam sulfat pekat menghasilkan lebih dari $98 \%$ dihidroksi atau polihidroksi asam lemak melalui hidrolisisnya. Khadijah 20146), membuat DHSA dari epoksidasi asam oleat melalui rute PFA menggunakan katalis asam sulfat dilanjutkan hidrolisis menggunakan air panas dan katalis alumina. Bahan baku yang digunakan dalam penelitian ini adalah asam oleat. Asam oleat salah satu asam lemak yang merupakan produk industri oleokimia dasar terpenting dengan jumlah produksi tertinggi. Bahan ini dapat disintesa menjadi berbagai produk turunannya, karena sebenarnya hampir semua produk oleokimia dasar dan hilir dapat diproduksi dari asam lemak, bahan ini merupakan bahan dasar dalam industri oleokimia.

Metode yang sering digunakan untuk mensintesa epoksida adalah reaksi dari suatu alkena dengan suatu asam peroksi organik. Epoksidasi juga dapat didefinisikan sebagai reaksi pembentukan gugus oksiran dengan cara oksidasi ikatan rangkap menggunakan oksidasi peroksi asam asetat dan katalis $^{7}$. Pada dasarnya ada 4 teknologi yang dikenal untuk menghasilkan epoksida dari olefin ${ }^{8)}$ : (1) Epoksidasi dengan asam perkarboksilat (Prileschajew), asam perkarboksilat dibentuk in situ oleh reaksi asam karboksilat dan hidrogen peroksida, dikatalisasi oleh asam atau enzim ${ }^{9,10)}$; (2) Epoksidasi dengan katalis peroksida organik dan anorganik ${ }^{11)}$; (3) Epoksidasi dengan halohydrines ${ }^{12)}$; (4) Epoksidasi dengan molekular oksigen ${ }^{12)}$.

Pemilihan asam format sebagai peracid di dalam penelitian ini, karena asam format lebih reaktif dibandingkan dengan asam asetat, karena kereaktifannya itulah yang memicu pembukaan cincin oksiran lebih cepat dibandingkan dengan asam asetat ${ }^{13)}$ yang akan membantu proses hidroksilasi. Asam format lebih disukai dari pada asam asetat sebagai pembawa oksigen karena reaktifitas tinggi, tidak diperlukan katalis dalam pembentukan asam performat ${ }^{14)}$. Urutan reaktivitas beberapa peroksi asam adalah $\mathrm{m}$-kloro perbenzoat $>$ peroksi format $>$ perbenzoic $>$ peroksi asetat ${ }^{15}$. . Metode Epoksidasi yang digunakan pada penelitian ini adalah Metode Epoksidasi In-Situ, menggunakan pereaksi asam format dan hidrogen peroksida.

Pada skala laboratorium reaktor $500 \mathrm{~mL}$ telah dilakukan penelitian epoksidasi asam oleat menggunakan asam performat yang dibentuk secara in situ dengan perbandingan molar asam oleat/asam format/hidrogen peroksida adalah $1: 1: 2,5$ dengan waktu reaksi 120 menit dan pada suhu $60-70^{\circ} \mathrm{C}^{16)}$.

Scaling up proses epoksidasi asam oleat dari skala laboratorium ke bench scale (kapasitas $5 \mathrm{~L}$ ) terjadi perubahan volume dan geometri dari peralatan yang akan mempengaruhi proses epoksidasi itu sendiri sehingga perlu dilakukan observasi terhadap parameter-parameter yang akan digunakan dalam basic dan engineering design.

\section{BAHAN DAN METODE}

Pada penelitian ini dilakukan optimasi scaling up epoksidasi menggunakan reaktor $5 \mathrm{~L}$ dengan variasi perbandingan reaktan, waktu reaksi dan suhu reaksi.

\section{Bahan}

Asam oleat teknis dengan kemurnian 77\% diperoleh dari PT. Cisadane Raya Chemicals, asam format dari PT. Brataco, larutan hidrogen peroksida $50 \mathrm{~b} / \mathrm{b} \%$ dari PT. Peroksida Indonesia Pratama, dan isopropil alkohol teknis dengan kemurnian 98\% dari PT. Brataco. Sedangkan bahan kimia yang lainnya untuk keperluan analisis diperoleh dari Merck. 


\section{Alat Percobaan}

Peralatan utama yang digunakan dalam penelitian ini adalah reaktor kapasitas 5000 $\mathrm{mL}$ yang dilengkapi pendingin balik dan pengaduk. Instrument Centrifuge Centurion Scientific C2 Series Centrifuges, digital buret, oven vacuum.

\section{Cara Pengolahan Data (Analisis)}

Analisa bilangan iodin (iodine value/IV) menggunakan standar AOCS Official Method Cd 1d - 92.

Perhitungan Bilangan lodin (IV $\mathrm{g} \mathrm{I}_{2} / 100$ g sampel):

Bilangan Iod $=\frac{\left(\mathrm{V}_{0}-\mathrm{V}_{S}\right) \times 12,69 \times \mathrm{N}_{\mathrm{Na}_{2} \mathrm{~S}_{2} \mathrm{O}_{3}}}{\text { berat sampel, } \mathrm{g}}$

Dimana $\mathrm{V}_{0}$ adalah $\mathrm{mL}$ volume $\mathrm{Na}_{2} \mathrm{~S}_{2} \mathrm{O}_{3}$ titran untuk blangko (tanpa sampel), $\mathrm{V}_{\mathrm{s}}$ adalah $\mathrm{mL}$ volume $\mathrm{Na}_{2} \mathrm{~S}_{2} \mathrm{O}_{3}$ titran untuk sampel, $\quad \mathrm{N} \quad \mathrm{Na}_{2} \mathrm{~S}_{2} \mathrm{O}_{3}$ adalah konsentrasi $\mathrm{Na}_{2} \mathrm{~S}_{2} \mathrm{O}_{3}$ yang digunakan $0,1 \mathrm{~N}$.

Data-data hasil percobaan epoksidasi yang berupa bilangan iod bahan baku asam oleat dan produk epoksi asam oleat selanjutnya diolah menjadi nilai konversi epoksidasi.

Penentuan konversi $(X)$ reaksi pada senyawa ikatan rangkap adalah ekivalen dengan bilangan iod (IV) ${ }^{17)}$, seperti persamaan berikut ini:

$\mathrm{X}(\%)=\left[\frac{\left(\mathrm{IV} \mathrm{V}_{0}-\mathrm{IV}\right)}{\mathrm{IV}}\right] \times 100$

dengan:

$I V_{0}=$ bilangan iod mula-mula (bahan baku asam oleat)

IV = bilangan iod produk epoksi

Bilangan iodin digunakan untuk menghitung bilangan oksiran teoritis (the theoretical oxirane oxygen content $\left(\mathrm{OOC}_{\mathrm{t}}\right)$.

Perhitungan bilangan oksiran teoritis, OOCt:

$O O C_{t}=\left[\frac{\left(I V_{0} / 2 A_{i}\right)}{100+\left(I V_{0} / 2 A_{i}\right) A_{0}}\right] A_{0} \times 100$

Dengan $A_{1}(126,9045)$ dan $A_{0}(16,0000)$ adalah berat atom iodium dan berat atom oksigen. IV 0 adalah bilangan iodin dari sampel mula-mula.

Analisis bilangan oksiran hasil percobaan (oxirane oxygen content/OOC $\mathrm{e}$ ) menggunakan AOCS Official Method Cd 957.

Perhitungan Bilangan Oksiran $\left(\mathrm{OOC}_{\mathrm{e}}\right)$ :
Bilangan Oksiran $=\frac{V_{s} \times 1,6 \times N_{H B r}}{\text { beratsampel, } g}$

Dengan $\mathrm{OOC}_{e}$ adalah nilai oksiran yang diperoleh dari hasil percobaan, $V_{s}$ adalah volume $\mathrm{HBr}$ titran untuk sampel, $\mathrm{N} \mathrm{HBr}$ adalah konsentrasi $\mathrm{HBr}$ yang digunakan 0,1 $\mathrm{N}$.

Bilangan oksiran ini digunakan untuk menghitung persen relatif konversi menjadi oksiran yaitu dengan menggunakan persamaan berikut:

$\%$ Oks $=\frac{O O C_{e}}{O O C_{t}} \times 100(5)$

Degradasi Oksiran $=100-\% O k \operatorname{siran}(6)$

Hasil perhitungan degradasi oksiran menunjukkan banyaknya cincin oksiran yang terbuka, semakin kecil oksiran yang terbentuk maka semakin kecil \% oksiran sehingga degradasi semakin besar ${ }^{17)}$. Epoksidasi dengan nilai degradasi oksiran yang besar (bilangan iodinine rendah) menunjukkan bahwa pada epoksi tersebut telah mengalami pembukaan cincin oksiran.

\section{Prosedur Kerja}

Pemilihan kondisi optimal berdasarkan tujuan reaksi epoksidasi yaitu pemutusan ikatan rangkap membentuk cincin epoksi/oksiran yang ditandai dengan nilai bilangan oksiran tinggi dan bilangan iodin rendah. Bilangan iod yang ingin dicapai yaitu $<1 \mathrm{~g} \mathrm{I}_{2} / 100 \mathrm{~g}$.

Basis reaktan adalah $1 \mathrm{~mol}$ asam oleat. Pada reaksi epoksidasi dengan komposisi 1 mol asam oleat dan $1 \mathrm{~mol}$ asam format, mol hydrogen peroksida yang digunakan variasi $1 \mathrm{~mol}, 4 \mathrm{~mol}, 5 \mathrm{~mol}$, dan $6 \mathrm{~mol}$.

Dilakukan variasi mol asam format dengan komposisi $1 \mathrm{~mol}$ asam oleat dan 6 mol hydrogen peroksida. Variasi mol asam format yang digunakan $1 \mathrm{~mol}, 1,25 \mathrm{~mol}, 1,3$ mol dan $1,5 \mathrm{~mol}$.

\section{HASIL DAN PEMBAHASAN}

\section{Optimasi Epoksidasi}

Epoksidasi In-Situ menggunakan pereaksi asam format dan hidrogen peroksida membentuk peracid yaitu asam peraformat. Data hasil percobaan terangkum di Tabel 1. 
Tabel 1.

Nilai-nilai Hasil Percobaan Epoksidasi yang Dicapai pada Epoksidasi Asam Oleat

\begin{tabular}{ccccccc}
\hline Run & $\begin{array}{c}\text { Mol Rasio } \\
\text { AO }: \text { : }: \text { : HP }\end{array}$ & $\left.\mathbf{T}^{\circ} \mathbf{C}\right)$ & $\mathbf{t}$ (menit) & $\mathbf{I V}^{\mathbf{a}}$ & $\mathbf{X}^{\mathbf{b}}$ & $\boldsymbol{O O C}_{\max }^{\boldsymbol{e}}$ \\
\hline 1 & $1: 1: 1$ & 65 & 75 & 14,368 & 82,77 & 1,35 \\
2 & $1: 1: 4$ & 65 & 75 & 2,596 & 96,89 & 2,76 \\
3 & $1: 1: 5$ & 65 & 75 & 1,561 & 98,13 & 3,20 \\
4 & $1: 1: 6$ & 65 & 75 & 1,063 & 98,72 & 1,11 \\
5 & $1: 1,25: 6$ & 65 & 75 & 0,933 & 98,88 & 1,17 \\
6 & $1: 1,3: 6$ & 65 & 75 & 2,088 & 97,50 & 2,17 \\
7 & $1: 1,5: 6$ & 65 & 75 & 2,676 & 96,79 & 0,27 \\
\hline
\end{tabular}

$a / V$ (iodine value), bilangan iod. IVO $=83,3867$ dengan OOCt $=4,994 \%$.

${ }^{b}$ Konversi ikatan rangkap, $X$.

\section{Pengaruh Peroksida \\ Konsentrasi}

Pada penelitian ini telah dilakukan reaksi epoksidasi dengan memvariasikan konsentrasi hidrogen peroksida untuk mengetahui pengaruhnya terhadap bilangan iodepoksi. Variasi yang dibuat yaitu perbandingan mol asam oleat : asam format : hidrogen peroksida $(1: 1: 1 ; 1: 1: 4 ; 1: 1$ : $5 ; 1: 1: 6)$. Pengaruh penambahan konsentrasi hidrogen peroksida terhadap bilangan iodin dapat dilihat pada Gambar 1 .

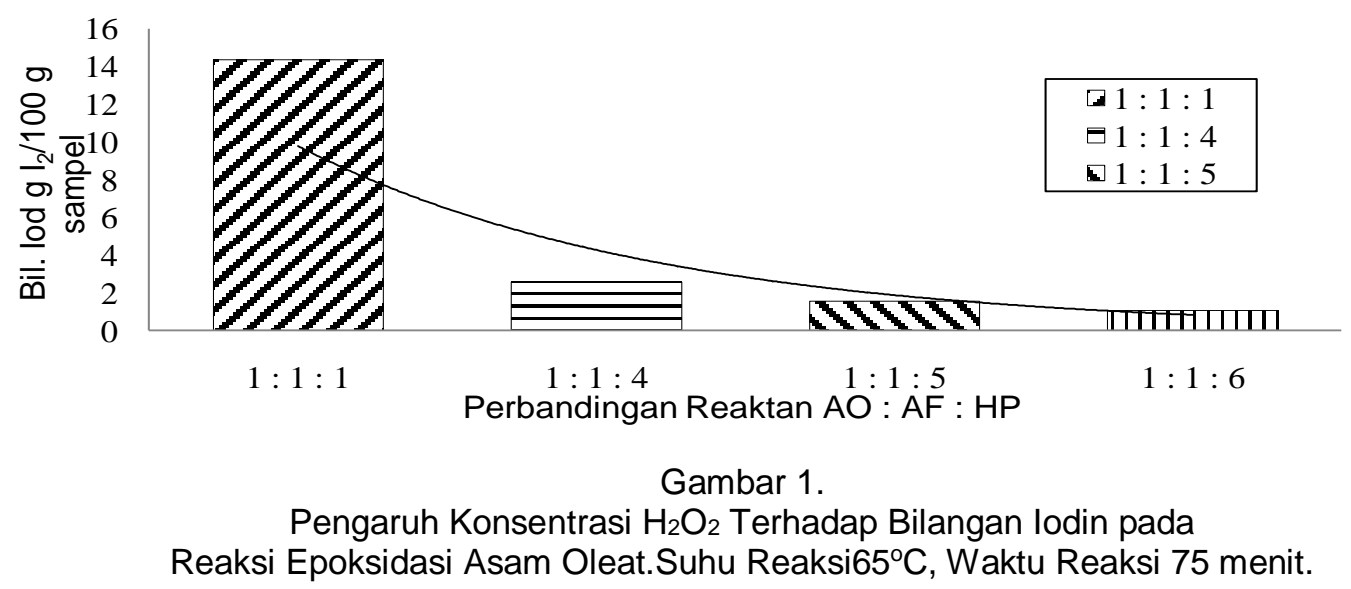

Pada Gambar 1 terlihat dengan peningkatan konsentrasi hidrogen peroksida 1 mol hingga 6 mol terjadi peningkatan progresif konversi yang ditandai dengan penurunan bilangan iod. Hidrogen peroksida merupakan pereaksi oksidasi yang baik dan apabila menggunakan pelarut asam maka reaksi oksidasi akan lebih cepat terjadi, apalagi bila dipanaskan ${ }^{18)}$. Hidrogen peroksida merupakan oksidan kedua terbesar setelah oksigen murni dengan kandungan oksigen aktif $47,1 \%-b^{19,20}$.

Reaksi epoksidasi asam oleat diawali dengan pembentukan asam performat yang dibentuk secara in situ yang merupakan reaksi reversible dan eksotermis. Peningkatan konsentrasi hidrogen peroksida akan meningkatkan pembentukan asam performat yang diikuti dengan peningkatan konversi epoksi. Penambahan konsentrasi asam format akan menyebabkan kesetimbangan reaksi bergeser ke kanan, yang artinya jumlah asam lemak yang terputus ikatan rangkapnya semakin banyak.

Namun penggunaan konsentrasi konsentrasi $\mathrm{H}_{2} \mathrm{O}_{2}$ yang sangat tinggi dalam epoksidasi menyebabkan cincin oksiran yang diproduksi sangat tidak stabil, sehingga meningkatkan produksi diol dan a-glikol sebagai produk samping ${ }^{21,22)}$, tetapi bagi penelitian ini ketidakstabilan cincin oksiran tersebut sangat baik sekali untuk proses selanjutnya karena cincin yang telah terbuka 
akan lebih mudah berikatan dengan hidrogen membentuk hidroksil.

Konsentrasi hidrogen peroksida optimum dalam penelitian ini adalah $6 \mathrm{~mol}$ (dalam perbandingan mol asam oleat : asam format $=1: 1$ ), yang ditunjukkan dengan bilangan iod 1,063 (Gambar 1) dankonversi $98,72 \%$ (Gambar 2).Selanjutnya, pada penelitian ini menggunakan perbandingan mol asam oleat dan hidrogen peroksida $=1$ : 6.

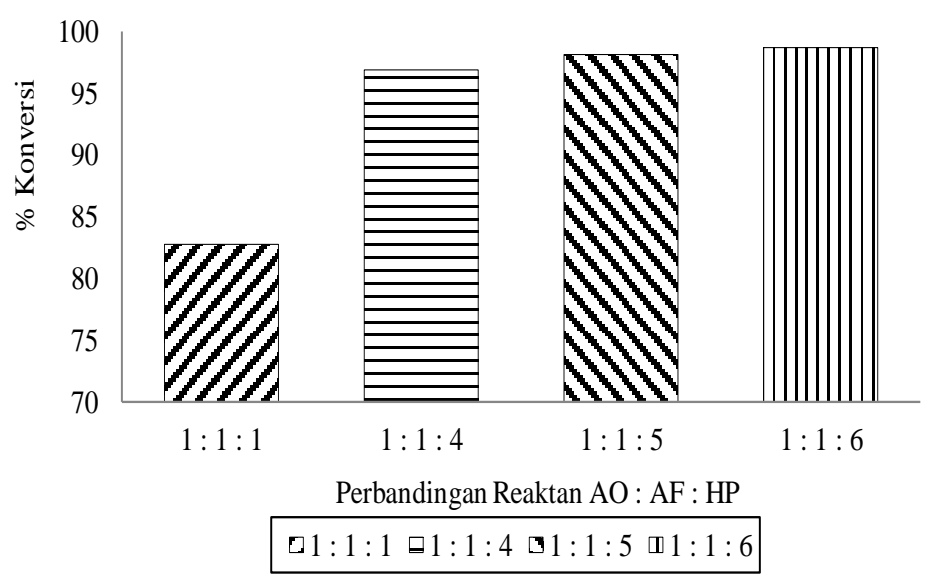

Gambar 2.

Pengaruh Konsentrasi $\mathrm{H}_{2} \mathrm{O}_{2}$ Terhadap Konversi pada Reaksi Epoksidasi Asam Oleat.Suhu Reaksi65으, Waktu Reaksi 75 menit.

\section{Pengaruh Konsentrasi Asam Format}

Berbagai rasio mol asam oleat : $\mathrm{HCOOH}: \mathrm{H}_{2} \mathrm{O}_{2}(1: 1: 6 ; 1: 1,25: 6 ; 1: 1,3: 6$ dan 1:1,5:6) dilakukan untuk mengeksplorasi pengaruh asam format pada epoksidasiasam oleat. Dalam pembentukan cincin oksiran, asam format dapat bertindak sebagai katalis dan sebagai reaktan dalam hidrolisis cincin oksiran ${ }^{23)}$. Untuk mencapai nilai oksiran maksimum, jumlah asam optimal harus digunakan di mana fungsi keduanya akan mempengaruhi produksi jumlah asam performat.

Gambar 3 menampilkan pengaruh mol asam format terhadap bilangan iod hasil epoksida. Peningkatan konsentrasi asam format variasi $1 \mathrm{~mol}, 1,25 \mathrm{~mol}, 1,3 \mathrm{~mol}$ dan $1,5 \mathrm{~mol}$, epoksidasi asam oleat mencapai bilangan iod terendah 0,933 dicapai pada perbandingan mol asam oleat : asam format : hidrogen peroksida $=1: 1,25: 6$.

Berdasarkan Gambar 3, penurunan bilangan iod asam oleat secara drastis terjadi pada penggunaan asam format 1,25 mol. Konsentrasi pereaksi cukup berpengaruh pada penurunan bilangan iod, yaitu semakin besar konsentrasi zat pereaksi (asam format), bilangan iod-nya semakin rendah. Hal ini karena semakin besar konsentrasi zat pereaksi maka frekuensi terjadinya tumbukan antara molekul-molekul yang bereaksi juga semakin besar.
Konsentrasi asam format berpengaruh pada pembentukan asam perfomat, karena selain sebagai reaktan, asam format juga berperan sebagai katalis dalam pembetukan asam performat. Semakin besar konsentrasi asam format yang digunakan kesetimbangan reaksi bergeser ke kanan sehingga asam performat yang terbentuk semakin banyak tetapi karena reaksi pembentukan asam performat ini merupakan reaksi eksotermis dan reversible, kesetimbangan dapat berbalik geser ke kiri yang menyebabkan asam performat terdekomposisi sehingga jumlahnya tidak lagi cukup untuk bereaksi dengan asam oleat secara optimal. Reaksi epoksidasi adalah reaksi eksotermis dan konsentrasi asam performat yang tinggi harus dihindari ${ }^{23)}$.

Meskipun meningkatkan jumlah asam format akan mempercepat epoksidasi, tetapi juga mempercepat pembukaan cincin oksiran. Asam format adalah pembawa oksigen yang baik dan penting untuk memproduksi epoksida dalam fase air, hal itu juga merupakan penyebab utama terjadinya hidrolisis cincin oksiran ${ }^{23)}$. Peningkatan konsentrasi asam format sampai dengan nilai tertentu dapat meningkatkan transfer oksigen aktif dari fase air ke fase minyak sehingga meningkatkan oksiran yang terbentuk. Penggunaan asam format yang berlebih dari kebutuhan optimal menjadi hal yang tidak berguna, karena pada 
reaksi epoksidasi nanti juga akan menghasilkan asam format.

Konsentrasi asam format optimum dalam penelitian ini adalah 1,25 mol per mol asam oleat yang ditunjukkan dengan konversi $98,88 \%$ (Gambar 4). Selanjutnya, pada penelitian ini epoksidasi $1 \mathrm{~mol}$ asam oleat menggunakan 1,25 mol asam format.
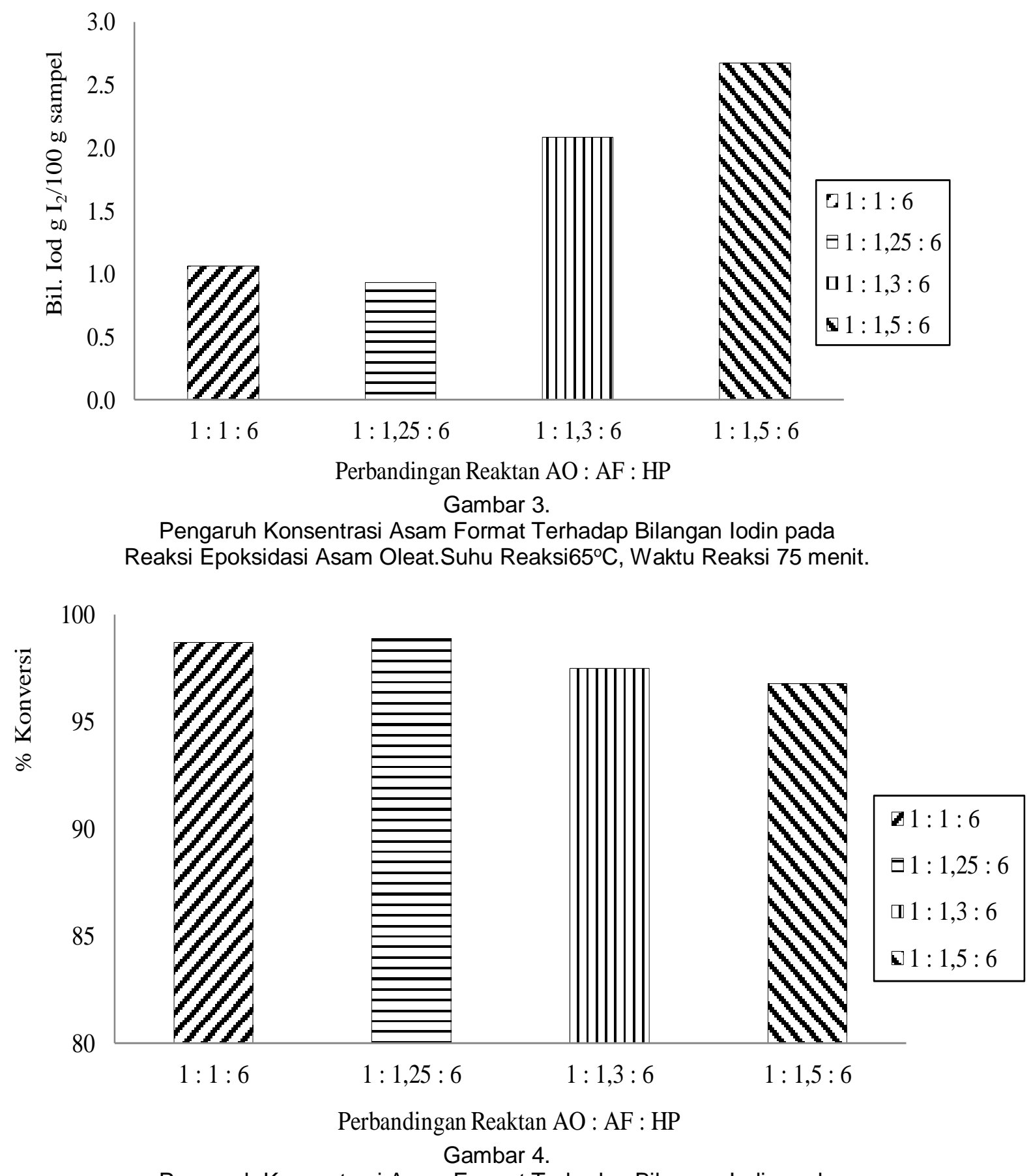

Pengaruh Konsentrasi Asam Format Terhadap Bilangan lodin pada

Reaksi Epoksidasi Asam Oleat.Suhu Reaksi65ํㅡ. Waktu Reaksi 75 menit.

\section{SIMPULAN}

Pada penelitian ini dilakukan scaling up proses epoksidasi asam oleat sebagai produk antara dalam sintesis DHSA dari asam oleat dari skala laboratorium ke bench scale (kapasitas 5 L), karena peningkatan kapasitas dari skala laboratorium ke bench scale akan terjadi perubahan volume dan geometri dari peralatan yang akan mempengaruhi proses epoksidasi sendiri sehingga perlu dilakukan observasi terhadap parameter-parameter yang akan digunakan dalam basic dan engineering design. 
Reaksi epoksidasi pada scaling up menggunakan reakor 5 liter, bilangan iod optimal/rendah (< 1 g la $/ 100$ g) 0,933 diperoleh pada komposisi reaktan dengan perbandingan mol asam oleat : asam format : hidrogen peroksida $=1: 1,25: 6$. Kondisi operasi epoksidasi asam oleat pada waktu reaksi 75 menit dan suhu $65^{\circ} \mathrm{C}$.

\section{UCAPAN TERIMA KASIH}

Ucapan terima kasih ditujukan kepada Kementeian Riset Teknologi dan Pendidikan Tinggi yang telah membiayai kegiatan ini melalui Program Insentif Riset Sistem Inovasi Nasional Tahun Anggaran 2017.

\section{DAFTAR PUSTAKA}

1. Koay, G. F. L., Abdullah, L. C., Yunus, R., Choong, S. Y. T., Siwayanan, P. \& Salmiah, A. (2006). Crystallization of dihydroxystearic acid (DHSA) produced from commercial grade palm oil based crude oleic acid employing isopropyl alcohol as solvent. International Journal of Engineering and Technology, 3, 115124.

2. Zafarizal Aldrin, A.H., Rosnah Ismail, and Salmiah Ahmad. (2005). Safety Evaluation for Dermal and Ocular Irritation of Palm Dihydroxystearic Acid as a Cosmetics Ingredient. Journal of Oil Palm Research vol. 17 December 2005, 160-167.

3. Fereidoon Shahidi. (2005). Bailey's Industrial Oil and Fat Products. Sixth Edition, Six Volume Set. John Wiley \& Sons, Inc.

4. Koay, G. F. L., Guan, C. T., ZainalAbidin, S., Ahmad, S. \& Choong, T. S. Y. (2009). Habit and morphology study on the palm-based 9,10dihydroxystearic acid (DHSA) crystals. Materials Chemistry and Physics, 114, 14-17.

5. Ahmad, S., Hoong, S., Sattar, N., Yusof, Y.M., Hassan, H.A., and Awang, R.,(2009). Palm-based hydroxy fatty acid. United States Patent No. US 7560578 B2. (Jul. 14, 2009).

6. Siti Khadijah Jamaludin, Noorfazlida Mohamed, Mohd Jumain Jalil, Ahmad Rafizan Mohamad Daud. (2014). Formation of Dihydroxystearic Acid from Hydrolysis of Palm Kernel Oil Based Epoxdized Oleic Acid. Journal of Applied Science and Agriculture, 9(11) Special 2014, 86-92.
7. Sinaga. (2007). Pengaruh katalis $\mathrm{H}_{2} \mathrm{SO}_{4}$ pada reaksi epoksidasi metil ester PFA (Palm Fatty Acid Distillate). Jurnal Teknologi Proses, 6 (1), pp. 70-74.

8. Turco, R. (2012). Industrial Catalytic Processes Intensification Through the Use of Microreactors. PhD Thesis in Chemical Sciences 24th cycle, Univerity of Naples Federico II. Departement of Chemistry. 21-30.

9. Klaas, MR and Warwel S. 1999. Complete and partial epoxidation of plant oils by lipase-catalysed perhydrolysis. Ind. Crops Prod. 9 (2):125-132.

10. Rios L.A., Weckes P., Schuster H., Hoeldrich W.F. (2004). Mesoporous and amorphous Ti-silicas on the epoxidation of an unsaturated oil or alkyl fatty acid ester. Pat. USA 6,734,315.

11. Sharpless KB, Woodard SS, and Finn MG. (1983). On the mechanism of titanium-tartrate catalyzed asymmetric epoxidation. Pure Appl. Chem. 55:1823-1836.

12. Guenther $S$, Rieth $R$, and Rowbottom KT. (2003). Ullmann's Encyclopedia of Industrial Chemistry, vol. 12, sixth ed. Wiley-VCH.

13. Jumat Salimon and Darfizzi Derawi. (2010). Optimizing on Epoxidation of Palm Olein by Using Performic Acid. Ejournal of Chemisty 2010, 7(4), 14401448.

14. Scala JL, Wool RP. (2002). The effect of fatty acid composition on the acrylation kinetics of epoxidized triacylglycerols. J Am Oil Chem Soc 79(1):59-63.

15. Karak. (2012). Vegetable Oil-Based Polymers: Properties, Processing and Applications. 188

16. Maisaroh, Indra Budi Susetyo, dan Bayu Rusmandana. (2016). Sintesis Asam 9,10-Dihidroksi Stearat (DHSA) melalui Hidrolisa Epoksida dari Oksidasi Asam Oleat dengan Asam Performat. Jurnal Reaktor, Vol. 16 No. 2, Juni Tahun 2016, Hal. 57-64.

17. A. Campanella, M.A. Baltan'as. (2005). Degradation of the oxirane ring of epoxidized vegetable oils with hydrogen peroxide using an ion exchange resin. Catal. Today 107-108, 208-214.

18. Underwood, A.L. and Day, R.A., Alih Bahasa: Aloysius Handyana Pudjaatmaka Ph.D. (1989). Analisis Kimia Kuantitatif. Edisi kelima, Penerbit Erlangga, Jakarta.

19. García-Marín $H$, van der Toorn JC, Mayoral JA, García JI, Arends IWCE. (2011).Epoxidation of cyclooctene and 
cyclohexene with hydrogen peroxide catalyzed by bis[3,5-bis(trifluromethyl)diphenyl]desenide: recyclable catalystcontaining phases through the use of glycerol-derived solvents. J Mol Catal A: Chem 2011; 334: 83-87.

20. Yang R, Zhang Y, Zhao J. (2011). Methyltrioxorhenium-catalyzed

epoxidation of alkenes with hydrogen peroxide as an oxidant and 1-methyl-3(butyl-4-sulfonate) imidazolium betaine as an additive. Catal Commun 2011; 12:923-6.

21. Dinda, S. Patwardhan, A.V., Goud, V.V. \& Pradhan, N.C. (2008). Epoxidation of cottonseed oil by aqueous hydrogen peroxide catalyzed by liquid inorganic acids. Bioresource Technology, 99: 3737-3744.

22. Gryglewicz, S., Piechocki, W. \& Gryglewicz, G. (2003). Preparation of Polyol Esters Based on Vegetable and Animal Fats. Bioresource Technology 87: 35-39.

23. A. Campanella, Carina Fontanini, Miguel A. Baltanas. (2008). High Yield Epoxidation of Fatty Acid Methyl Ester with Performic Acid Generated In Situ. Chem. Eng. J144, 466-475. 